\title{
Data Quality, Power, And Politics: Analysis Of Strategic Decision Making
}

Andrew B. Nyaboga, (E-mail: nyabogaa@wpunj.edu), William Paterson University

Muroki F. Mwaura, (E-mail: mwauraa@wpunj.edu), William Paterson University

\begin{abstract}
Most decision makers have biases that are inherent the way they seek information, estimate the outcomes, and attach values to outcomes that produce rational behavior. Many aspects of decision-making may not be accurate because of information processing limitations, power and politics. This paper presents a set of ideas, models, and limitations caused by biases of a decision maker when sorting information.
\end{abstract}

\section{Introduction and Literature Review}

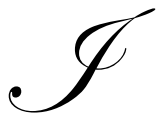

$\mathrm{s}$ it power and politics that determine the way managers make strategic organizational decisions or is it the quality of information received from their data processing departments? Making strategic organizational decisions is a complex process and is considered to be at the heart of information processing. Decision-makers evaluate alternatives and choose a course of action that may be covert or overt and can be recognized (Sanders et al. 1993). Data used by managers to make strategic decisions is collected by individuals lower in the vertical hierarchy. Once the data is gathered, it must be interpreted to have a valuable meaning. The interpretations are communicated to the end user who can be either an external or internal customer. These external or internal data customers use the data, which has been interpreted for them by the operational level staff. Some of the data, which has been manufactured and interpreted, is of poor quality. Additionally, human beings are not optimal decision makers and they usually don't act rationally, which means they don't act according to objective properties of gain and loss.

Decision making is found in any operational environment, e.g., forecasting the weather, diagnosing a patient, within business organizations and in consumer behavior. All these have diverse effects but they possess certain common elements. Making decisions for an organization involves seeking information relevant to the decision at hand (Sanders et al. 1993). Whether you want to predict the weather or predict the outcome of general elections, getting relevant information is paramount. However, most decision makers have biases that are inherent in the way they seek information, estimate probabilities, and attach values to outcomes that produce irrational behavior (Sanders et al. 1993). Additionally, many aspects of decision making are not accurate because of limitations of information processing, politics, and power. Power and politics have been defined as who gets what, when and by what methods. In most organizations, power is recognized by the ability of those who possess it to bring about the outcome, which meets their goals or desire.

This paper addresses the question of politics, power, data quality dimensions and strategic decision making. As indicated earlier, the definition of power includes an element indicating that power is the capability of one social action to overcome resistance in achieving a desired objective or result (Jeffrey Pfeffer 1981). Dahl (1957) defined power as "a relationship among social actors" whereby one social actor tells another social actor to act on something which he would have not done otherwise. For example, the board of directors of an organization may force the chief executive officer (CEO) of the company to implement decisions regardless of the information received from the data processing department. The CEO then will attempt to influence decisions over critical issues that are not resolved through the use of available information.

Readers with comments or questions are encouraged to contact the authors via email. 
It has been argued that where there is no agreement over the goals and objectives of an enterprise, compromise may be used or otherwise judgment may be employed. The tragic incidents where compromise and poor judgment were employed include the launching of the shuttle Challenger in 1985. Although the data gathered showed that the weather was not conducive, the Challenger was launched anyway. The result was a disaster and a loss of the entire crew (AP Monitor, 1988). In 1987, the USA Navy vessel, USS Vincennes, shot down an Iranian civilian airliner after having erroneously classified a radar signal as an enemy aircraft; the result was the loss of 290 lives (US Navy, 1988). The launching of the Challenger was due to bad decision-making concomitantly with the politics of economics. The shooting down of the Iranian civilian airliner was caused by poor data gathered and interpreted by lower level echelons. This indicates that decisions of an organization may be determined by power, politics and gathered data.

\section{A Model Of The Decision-Making Process}

All decision-makers sample a number of cues or information sources from the environment. The information gathered may be right or wrong for the decision maker. Decisions are made to achieve the enterprise goals, either by using the gathered information or using rules and procedures that may have evolved in an organization. When rules and procedures are involved, the quality of data is non-existent.

Figure 1 depicts the information processing model and how power and politics play a major role in decision-making. As indicated in the figure, data is gathered from the environment and the input of the information establishes the parameters of what is to be done. Robbins (1990) noted that the interpretations of information are transmitted to the advisor who is higher on the vertical hierarchy, who then makes use of the information for decision making. Decision-makers are usually CEOs, those who are highest in the vertical hierarchy and who are in frequent contact with the board of directors of the organization. The interests of the decision-makers and those of an organization are usually not the same. Decision-makers act in their self-interest; therefore, their choices reflect only the criteria and preferences compatible to their objectives. As can be seen from Figure 1, data is captured from the environment, input into the system and then interpreted. Decision-makers are not the interpreters of the data; hence they have access only to the end-product information presented to them. In other words, much of the choosing has already been done before it is transmitted to the decision maker. Whether the information transmitted is of poor or good quality has no bearing because it is captured, screened and interpreted at points A, B and C respectively and the decision is made at point $\mathrm{D}$. This means that decision-makers use information whose quality is not known. Once the choice has been made, it is then authorized and conveyed before it is executed. The final output may not be what was desired. If the outcome is not satisfying, power and politics emerge, where judgment, compromise, and inspiration provide both the sufficient and necessary means of resolving the conflict.

Figure 1:

\section{Decision Making Model}

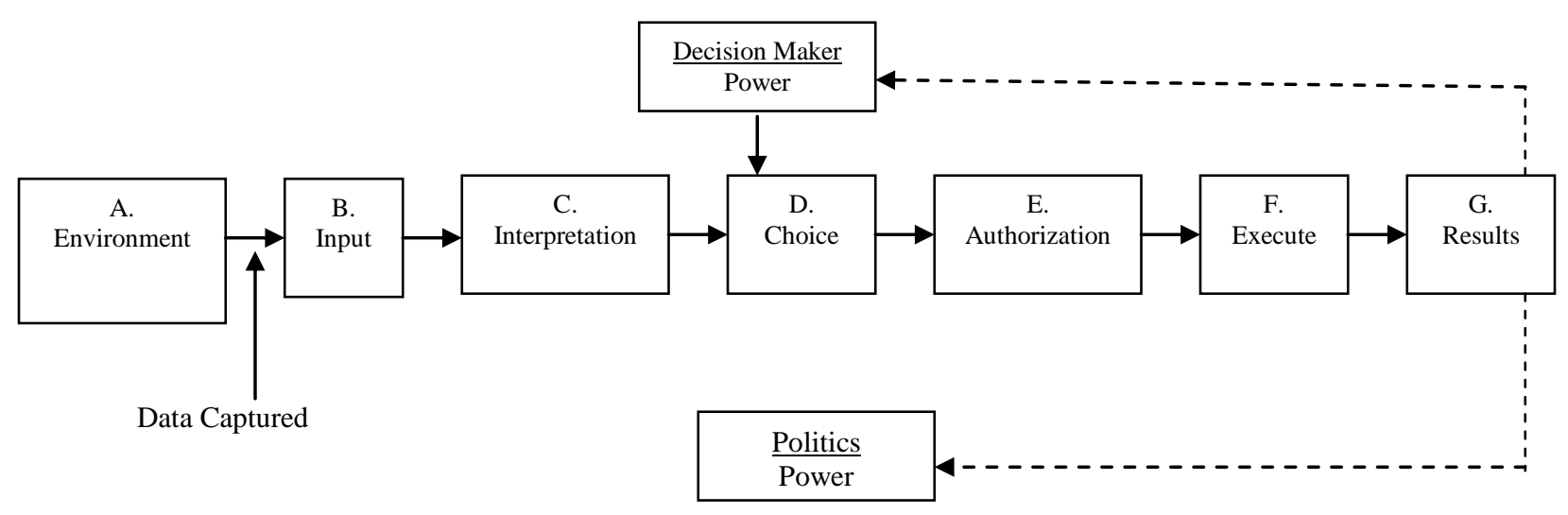


Decision-making tasks vary greatly in their difficulty (Wickens, 1984). Human beings also will try to increase gains or reduce losses when making decisions. In the information processing model in Figure 1, a decisionmaker's awareness of the outcome of prior decisions, whether successful or not, may influence the decision to be made due to that person's knowledge or improvement of the current plans (Wickens, 1984).

Many aspects of decision-making are not accurate because of limitations of information processing and memory. People make or adopt decision-making heuristics or mental shortcuts which means decisions can be made without regard to the quality of information. More information processing may not improve decision making because human beings will always employ a selective filtering strategy to process information cues. If few cues are initially presented, filtering may not happen; however, if several sources are presented, then the filtering process may be required, thus taking away resources from the integration of information (Wickens, 1984).

\section{Data Quality and Decision Making}

Managers, regardless of where they are in an enterprise, profit or non-profit, make decisions. All managers make choices among the goals of the organization. Although data and information are crucial to the everyday enterprise operation, they are often of very low quality. In most organizations, there is insufficient attention to this essential problem of data quality. Despite the use of System Development Life Cycle (SDLC), the results have not been encouraging for business operations and have led to alienation of customers.

Addressing the problem of data quality requires understanding the data and data management relation. Data quality is necessary to those who own it, manage it and use it. To understand data quality, we need to define what data is and its dimensions. Data is defined as a triple: <entity, attributes, values> (Lochovsky et. al.,1982). Data quality may be defined thus: 'a product or service (say A) is of higher quality than another product or service (say B), if A meets the customer's wants, more than B.”

Data quality dimensions include the following: accuracy, consistency, currency, timeliness, completeness, and precision.

- Accuracy - The degree of agreement between particular values or a set of values and an identified source, which supplies values, e.g., given:

A datum ' $\mathrm{d}$ ' defined by triple $<\mathrm{e}, \mathrm{a}, \mathrm{v}>$ and the corresponding real-world value $\mathrm{V}^{1}$

' $\mathrm{d}$ ' is accurate iff $\mathrm{V}=\mathrm{V}^{1}$

Other related notions of accuracy are precision (granularity of domain elements) and reliability - the statistical measure of the probability of correctness, also used as a synonym for overall data quality and also accuracy.

- Consistency - The degree to which required synchronization between two triples is achieved. Consistency does not mean correctness or accuracy. If two triples are inconsistent, then one must be inaccurate.

- Currency - The degree to which a specific piece of data is up-to-date. The datum is up-to-date at time ' $t$ ' if accurate at time ' $t$ '. The datum is out-of-date at time ' $t$ ' if not accurate at time ' $t$ ' and accurate at time ' $t$ '

- Timeliness $(T)$ - Defined as "the recorded value is not out of date" (Balou \& Pazer, 1985). It has two components: currency $(\mathrm{C})$ and volatility $(\mathrm{V})$; currency means the age of a datum and volatility means the rate at which a datum becomes obsolete or useless. Timeliness is annotated by the formula:

$\mathrm{T}=\sqrt{ } \mathrm{VC}$

If you double $\mathrm{V}$ and $\mathrm{C}$, you must double $\mathrm{T}$.

- Completeness - Defined as "when all values for a certain variable are recorded." Also defined as "when real world states one wishes to model are captured in the representing information system" (Wang etl.1994).

- Precision - Refers to having distinct representations for any two elements that must be distinguishable to the user. Precision is pertinent for quantitative data.

\section{The Impact of Biases in Decision Making}

In the decision-making process model of Figure 1, the choice made by the decision-maker is determined by 
the situation in which the decision-maker finds himself during the process. Additionally, some biases are inherent in the way information is sought by individuals, estimating probabilities and at the same time, attaching values to outcomes that produce the results (Sanders et al., 1993). The biases explicitly explain why human beings do not always make the best decisions, even though they had enough information to do so. Wickens (1984) has indicated the following biases:

a) Human beings will always seek information that will confirm their thinking and will try to avoid any information that will bring conflict. The interests of a decision maker and those of the enterprise are different. Decision-makers will always act in their self-interest; once their choice is satisfying, the search for additional information stops immediately.

b) Human beings will always seek more information than they can absorb. People have difficulty remembering more than about five to nine different standards against which stimuli must be judged (Sanders et al., 1993). In this connection, Miller (1956) referred to the magical number $7 \pm 2$. There is a limit on the human capacity to process and evaluate information in order to arrive at optimum decisions.

c) Decision-makers treat information as if it were equally reliable, even thought it is not. As mentioned earlier, decision-makers adopt "decision-making heuristics." When all the information has been given to the decision-maker, it is treated as if all the information had the same weight.

d) People give different amounts of weight to earlier evidence while negating subsequent information. Thus, different alternatives are never considered even though they might offer relevant solutions to the problem at hand.

e) Human beings are generally conservative and don't extract as much information from the source to help them in decision-making as they optimally should.

f) People will always focus on a few critical issues at a time, considering approximately two to five of the highest-ranking choices and rejecting other available possibilities.

\section{Bringing It All Together}

Decision-making is the process of making choices to attain the desired objectives. Choices are made after evaluating alternatives and choosing the preferred alternatives. Information must be gathered from the environment and input into the system for interpretation. The third step is to act on the advice in order to choose the alternatives. It is clear from Figure 1 that choosing is performed by the lower level personnel who gathered and interpreted the data. This means data quality, power and politics may be used inclusively or exclusively to obtain a preferred outcome in an enterprise. Power is the ability of those who posses it to bring about the outcomes that meet their objectives. Politics is defined as who gets what, when and how. Data quality dimensions include the following: accuracy, relevancy, timeliness, reliability and precision. Decision-makers may make choices depending on personal objectives that the individual wants to achieve. The politics of an enterprise may also have some influence on which decisions are made and how to accommodate a decision-maker's power within the enterprise. The quality of data received may influence the selection of choices by the decision-maker. The organizational politics involve intentional acts of influence to protect one or a group of interests. Therefore, decisions are made to achieve certain objectives; either by relying on the best information or by employing the rules and procedures of the company.

The purpose of this study is to investigate the relationships among power, politics and the dimensions of data quality. On the basis of the arguments discussed above, we then would expect to find that power and politics play a major role in determining the selection of choices. The decision-maker needs power to control business operations and power will only come by making decisions that protect his or her interests. The interests of a decision-maker include defending the interest of the organization, which may differ from that of the stockholders.

\section{Summary and Conclusion}

Decision makers act in their self-interest. The choices made by decision makers will reflect their preference and those choices, which meet their objectives. One's ability to influence is determined by the power he or she has acquired within the organization. Power is a structural phenomenon. The powers of a manager in an organization depend on where he or she stands in the vertical hierarchy of the organization. The politics of an organization involve those activities within the enterprise. The stockholders use politics and other resources to 
obtain the preferred outcome. When there is uncertainty about the given information, the decision makers and stockholders use their influence to get something accomplished. The political activity is undertaken to overcome some opposition within the company.

Decisions are made to achieve the organization's objective either by relying on the quality of the data or using normal standard operating procedures. Some of the decisions made are determined by the situation in which the decision makers find themselves. If politics are introduced into a situation, rationality disappears.

\section{References}

1. APA Monitor. 1988. Vincennes: Findings could have helped avert tragedy. Scientists tell Hill Panel.

2. Balou, D.P. \& Pazer, H.L. 1985. Modeling data and process quality in multi-input, multi-output Information systems. Management Science. 31(2), 150-162.

3. Dahl, R.A. 1957. The concepts of power. Behavioral Science. 2, 201-215.

4. Lochovsky, F.H. \& Tsichritzis, D.C. 1982. Data Models. Englewood Cliffs, N.J. Prentice Hall.

5. Miller, G. 1956. The magical number seven, plus or minus two: some limits on our capacity for processing information. Psychological Review. 63, 81-97.

6. $\quad$ Pfeiffer, J. 1981. Power in Organizations. Pitman Publishing.

7. Robbins, S.P. 1990. Organization Theory, Structure, Design and Applications. Englewood Cliffs, N.J. Prentice Hall.

8. Sanders, M.S. \& McCormick, E.J. 1983. Human Factors in Engineering and Design. McGraw- Hill, Inc. New York.

9. U.S. Navy. 1988. Investigation Report: Formal investigation into the circumstances surrounding The downing of Air Flight 655 on July 3, 1988. Washington, D.C. Department of Defense Investigative Report.

10. Wang, R. \& Wang, Y. 1994. Anchoring data quality and context through extension of ER Model. MIT Sloan School of Management.

11. Wickens, C. 1984. Engineering Psychologies_and Human Performance. Merrill. Columbus, $\mathrm{OH}$. 
Notes 